\title{
How Social Support and Foreign Language Anxiety Impact Willingness to Communicate in English in an EFL Classroom
}

\author{
Ammara Kalsoom ${ }^{1}$, Niaz Hussain Soomro ${ }^{2} \&$ Zahid Hussain Pathan ${ }^{3}$ \\ ${ }^{1}$ Department of English Literature, University of Balochistan, Quetta, Pakistan \\ ${ }^{2}$ Department of English Linguistics, University of Balochistan, Quetta, Pakistan \\ ${ }^{3}$ English Language Centre, University of Balochistan, Quetta, Pakistan \\ Correspondence: Ammara Kalsoom, Department of English Literature, University of Balochistan, Quetta, \\ Pakistan. E-mail: ammarakalsoom@yahoo.com
}

Received: October 29, 2019 Accepted: December 13, 2019 Online Published: January 18, 2020

doi:10.5539/ijel.v10n2p80 URL: https://doi.org/10.5539/ijel.v10n2p80

\begin{abstract}
This study investigates the impact of social support and foreign language anxiety (FLA) on learners' willingness to communicate (WTC) in English (L2) inside the classroom in an EFL context of Pakistan. The study administered adapted questionnaires on willingness to communicate (WTC), social support and foreign language anxiety (FLA) to 200 undergraduates of University of Balochistan, Quetta, Pakistan. To analyse the data, both descriptive and inferential statistics were performed in the SPSS. The findings on the social support revealed that father's support, teachers' support, best friends' support, and other friends' support exerted impact on learners' L2 WTC. Additionally, anxiety also negatively and significantly predicted L2 WTC with a medium effect size $\left(f^{2}=.26\right)$. These findings signify that provision of social support and means to minimize L2 anxiety can help L2 learners enhance their volitional readiness for L2 communication. The findings of this study have implications for EFL classroom participation in the target language and offer an insight for the policy and planning for the use of English language in an EFL context.
\end{abstract}

Keywords: willingness to communicate, social support, foreign language anxiety (FLA), postgraduate students

\section{Introduction}

The main purpose of learning a foreign language is to communicate effectively. Willingness to communicate (WTC) has emerged as one of the most dominant topics in the study of second language (L2) learning. Researchers claim that effective communication in L2 was the main objective of language learners (de Saint Léger \& Storch, 2009; MacIntyre, Burns, \& Jessome, 2011). One of the ultimate objectives of second language education is to create WTC among L2 learners in order to communicate proficiently (MacIntyre, Dörnyei, Clément, \& Noels, 1998). Linguistic competence, however, does not predict WTC of second language learners because there are some L2 learners with minimal linguistic competence who are more frequent in L2 communication than the ones with high level of linguistic competence (MacIntyre et al., 1998). MacIntyre and Doucette (2010) claimed that language-teaching strategies, in this era, focus on engaging the learners in oral communication inside the classrooms; however, there are language learners who are reluctant to communicate in second language. Learners may be reluctant to engage themselves in activities that involve authentic oral communication in L2 in a variety of contexts (Liu, 2005; Peng, 2012). There are some important factors such as anxiety, cultural differences, and lack of proficiency, which may lead to unwillingness. Research studies in different countries including China (Liu \& Jackson, 2009), Japan (Andrade \& Williams, 2009; Watanabe, 2013), Iran (Riasati, 2012) and Pakistan (Khan, 2013; Shamim, 1996, 2008) support this argument about the unwillingness of Asian students to communicate in English.

An empirical evidence shows that language proficiency, anxiety, and motivation do not solely predict the decision of students to participate or not to participate in speech activities conducted in L2 classroom (Boo, Dörnyei, \& Ryan, 2015; Dörnyei, 2009). For example, a proficient and motivated learner may unexpectedly choose to remain silent in the classroom. On the contrary, a learner who is less competent may surprisingly decide to frequently use L2 (MacIntyre, Baker, Clément, \& Conrod, 2001; Matsuda, 2012). Although Dörnyei (2003) mainly emphasized on the significance of learners' competence in the target language, he also argued that 
learners' WTC in the target language was equally important. Therefore, linguistic competence of students in L2 may not guarantee that they will be successful users of target language. This issue, thus, eventually necessitated the conceptualization of students' WTC in English inside the classroom. WTC was proposed as an immediate forecaster of L2 use.

According to Ajzen and Fishbein (1980), attitudinal aspects and social factors influence behavioural intentions of L2 learners. This hypothesis by Ajzen and Fishbein (1980) is applicable to Pakistani context too because the phenomenon of language acquisition/learning eminently depends on social context. Keeping this in view, the current study was conducted in Pakistani EFL context among postgraduate students of University of Balochistan (UoB). Considering its importance in learners' WTC in L2, social support for language learning was also included to be studied. The sources of social support include teachers, parents, siblings, and friends. In the Theory of Planned Behaviour by Ajzen (1991), these people are described as the extremely important referents for attitudes. L2 learners' WTC is likely to develop in the presence of support from these sources. Therefore, it may be argued that social support is an important factor towards learners' WTC in a target language.

Language anxiety is considered to have an impact on students' L2 learning. The level of fear and tension in anticipated communication is counted as an anxiety. An individual may experience anxiety in a group, or with another individual, while communicating in L2. Some studies in ESL and EFL context show that there is a negative relationship between language anxiety and WTC in L2. Increase in one variable may mean decline in the other variable. For example, low level of anxiety refers to increased level of L2 WTC in an individual (Baker \& MacIntyre, 2000; Kim, 2004; Yashima, 2002). Many other psychological variables, such as hesitation and perceived communication competence, determine language anxiety among L2 learners. These can be seen in classroom and conversational and interlocutor environments (Cao \& Philp, 2006; Peng, 2012).

MacIntyre, Baker, Clément and Donovan (2002) conducted a research study at a university in Canada. They selected immersion and non-immersion L2 learners of French as the participants of their study. The findings showed that immediate predictor of non-immersion students' WTC in L2 was perceived communication competence. Immersion students' WTC in L2 had a strong nexus with their motivation to learn L2 and their prior learning experiences. Accordingly, there was a direct relationship between learners' motivation and their WTC in L2. High level of motivation resulted in high frequency of L2 WTC among the participants of the study. Another mixed method study was conducted in Japanese context where foreign language anxiety of Japanese learners stated an inalienable relationship between classroom environment and learners' anxiety (Effiong, 2013). According to the study, anxiety severely inhibited the oral communication of learners in L2 classroom. There were many contextual factors responsible for L2 anxiety among learners. The literature on L2 anxiety also shows that motivation and anxiety co-determine L2 WTC (Bernales, 2016; Macintyre et al., 2011).

\subsection{EFL Model by Wen and Clément (2003)}

Wen and Clément presented this model in 2003. It is considered a very influential model in the field of WTC in EFL contexts. Wen and Clément (2003) applied the heuristic model of L2 WTC proposed by MacIntyre and associates (1998) to an EFL context. They viewed that cultural and social orientations of China had a great influence on L2 WTC of Chinese learners. Submissive ways of learning and other-directed self were two factors, which seemed to influence their WTC. Firstly, submission to the teacher's authority was a cultural feature that was inhibiting Chinese students' L2 WTC. Secondly, the roots of other-directed self were in collectivist orientation of Chinese culture. Some social and psychological barriers did not let learners communicate in L2 with other individuals.

The heuristic model by MacIntyre et al. (1998) presented some structural variables. According to Wen and Clément (2003), those variables were not same in the EFL context of China. According to heuristic model, desire to communicate (DC) was considered the direct antecedent of WTC. Whereas, this model describes that personality factors, affective perception, social context, and motivational orientations intervene the path between DC and WTC in L2. Accordingly, there are four categories of variables that interfere the transition of a language learner from DC to L2 WTC. These four categories of variables are named as social context, motivational orientations, personality factors, and affective perceptions (Wen \& Clément, 2003). Teacher support and group cohesiveness have an impact on L2 WTC of a learner in social context. Group cohesiveness can be described as the motivation and affiliation of an individual with a specific group in the context of a classroom. Teacher support is taken in a broad spectrum in which his/her involvement, immediacy, and attitude are considered. Teacher's involvement is described as the quality of interaction between teacher and learners in L2 classroom. Teacher immediacy involves the readiness to pay heed to learners' demands. Thus, a teacher's role as an interlocutor in a Chinese setting is highly influential. 
Moreover, personality factors intervene with L2 WTC of learners. One personality factor is risk-taking. It refers to the decision of a learner that whether he/she wants to use L2 or not. A learner's L2 WTC additionally varies relying upon his/her acceptance and/or avoidance of conversational situations. Motivational orientation is linked to affiliation and task orientation. An individual's desire to be a part of a group for communication purposes is considered as his/her affiliation. It is found to have a close nexus with affiliation motives as discussed by MacIntyre et al. (1998). Task orientation refers to a platform where learners engage in meaningful conversations with other people.

In Chinese EFL contexts, Chinese learners are very conscious about their L2 evaluation. Therefore, they do not engage in tasks about which they have a fear of negative evaluation. At the end, affective perception is related to inhibited monitor and positive expectation of evaluation. When a learner intentionally tries to apply L2 grammatical rules while speaking, it is called inhibited monitor. According to this model, Chinese EFL learners face the fear of negative evaluation; therefore, they extensively use this inhibited monitor. It acts as a barrier in their L2 production. They expect positive response from the individuals they are communicating with (Syed, 2016). By using Chinese EFL context, this model broadened the concept of L2 WTC. It gave a new lens to look at the field of L2 WTC. This model is applicable in EFL contexts of other countries as well. It suggests all the above-mentioned factors like personality factors, motivational orientations etc. collectively facilitate learners' L2 WTC.

\subsection{Past Studies in the Field of L2 WTC in Asian EFL Context}

Many research studies have been conducted in EFL context of Asian countries in recent years to determine learners' L2 WTC. Asian region is culturally and linguistically very versatile region and is a home to some of the world's oldest civilizations. In this era where USA is the world's most powerful country, English is considered the language of power. The need to learn English in Western and non-Western contexts grabbed the attention of research scholars as L2 learning is affected by contextual, psychological, and linguistic variables. In this section, some past studies in the field of L2 WTC in Asian context are discussed due to their similarity with Pakistani EFL context.

Many studies were conducted in Iranian EFL context, which focused on finding L2 WTC construct among Iranian university students. A study by Ghonsooly, Khajavy and Asadpour (2012) conducted a study with non-English major Iranian university students. Fallah (2014) conducted a research study in which he collected data from English-major Iranian university students. Zarrinabadi (2014) also conducted a research study in Iranian EFL context, which aimed at finding the impact of teacher related factors on Iranian learners' L2 WTC in classrooms. The participants of this study were also English-major Iranian university students. Communication anxiety and motivation affected learners' WTC in English. A negative correlation between anxiety and WTC was found out. Motivation had a significant impact on WTC of L2 learners. The results of the study by Zarrinabadi (2014) demonstrated that teacher had a huge impact on learners' WTC towards English in classroom. This study gave a new perspective in the field of L2 WTC that teacher had a strong impact on learners' willingness or unwillingness to communicate in English in the classrooms. The results of these studies were consistent with those of previous studies in EFL contexts. The results described L2 WTC to be a complex concept: affected by other variables.

In Korean EFL context, a research study was conducted to determine L2 WTC of Korean secondary school students (Joe, Hiver, \& Al-Hoorie, 2017). This study aimed at integrating three theoretical frameworks: classroom social climate, self-determination theory (SDT), and WTC in L2 in an EFL context of Korea. The study collected quantitative data from 381 Korean secondary school learners who were learning English as a foreign language. The results of the study demonstrated that communicative competence was found to be a strong predictor of WTC in L2 and L2 achievement. Classroom social climate of Korean secondary schools strongly predicted basic psychological needs of L2 learners. This finding indicated that context was a very important factor in determining learners' L2 WTC. Classroom situations where students were relaxed and had their teacher's emotional support were found to be highly willing to communicate in English in classrooms. Whereas, classroom situations where learners felt overly constrained and did not have active support of teacher hindered learners' WTC in English in classrooms. This study did not support the claim by other research studies that learners with higher WTC perform better in L2 in classroom settings. The researchers of this study claimed that WTC did not have a direct impact on L2 achievement in educational settings. Nature of actual opportunities to use L2 determined learners' WTC in L2.

Lin (2019) recently conducted a study in EFL contexts of Taiwan: An East Asian country. He tried to investigate WTC of Taiwanese EFL learners and the variables that influenced their L2 WTC. The participants of this study 
were 701 undergraduate students from a university in Taiwan. All the participants had prior formal education in English before entering into university. Just like any other EFL context, the ultimate goal of learning English, for Taiwanese learners, is to be able to communicate in this international language. English is confined to classroom settings because in EFL contexts students merely get a chance to communicate in English outside the classroom. Questionnaire was used as a data collection instrument. The findings of the study were similar to those of other studies in Asian EFL contexts. The learners were found motivated to learn English once they developed an international perspective about their career and importance of English in their bright career in this globalised world of 21st century. The findings of the study demonstrated that motivation of learners had a direct influence on their communication confidence and an indirect influence on their WTC in English in EFL contexts. In motivation, factor extrinsic motivation was more influential than intrinsic motivation. The reason behind it is the fact that in EFL context the driving force to learn English is mostly academic achievement and bright career. Lin (2019), in this study, discussed the influence of affective factors, communicative competence, and motivation on Taiwanese EFL learners' L2 WTC.

Shao and Gao (2016) reviewed selected articles published in System journal between 2000 and 2015 in which the researchers made different claims about reticence and WTC of East Asian EFL learners in L2. They reviewed articles written in East Asian contexts including Korea, Japan, Korea, China, Hong Kong, Macau, New Zealand, and Taiwan. All of these East Asian countries provided EFL context to English language learners. The findings of the selected articles demonstrated that when and how learners of these countries were unwilling or willing to communicate in English in classrooms. This special editorial discussed the necessity of bringing reforms in language classrooms and discussed the role of language teachers, which they play in the process of English language learning. This editorial is of great importance in Asian EFL context as it brings forth the issue of learners being passive learners and reticent in language classrooms. There is a perception that English language learners in East Asian region are reticent to communicate in English in classrooms due to some cultural barriers because the culture they live in hinders them to communicate in a foreign language. Their reticence and WTC are not solely driven by cultural perspective, rather the reasons behind their unwillingness and WTC need to be understood in relation to historical, social, and cultural conditions of East Asia.

\section{Method}

The present study used quantitative research design. It used questionnaire to collect data from participants. The study used statistical analysis and regression analysis of results of questionnaire data in order to describe the impact of social support on participants' English WTC inside the classroom and the impact of anxiety on participants' English WTC inside the classroom. Quantitative research design leads to gather information that is based on exact facts. Results obtained from the quantitative data analysis of the questionnaire provided a complete and deeper insight into tertiary students' WTC in English.

\subsection{Participants}

Data were collected from students registered in masters' degree programs of eight different departments for the present study. The reason behind choosing different departments for data collection was to determine the impact of social support and FLA on the University of Balochistan (UoB) students' L2 WTC inside the classroom. By collecting data from various departments, the results of the study could be generalised.

Cluster random sampling method was used to select the participants of the present study. This form of sampling was used for the convenience. Johnson and Christensen (2008) defined it as "a form of sampling in which clusters (a collective type of unit that includes multiple elements, such as schools, churches, classrooms, universities, households, and city blocks) rather than single unit elements (such as individual students, teachers, counsellors, administrators, and parents) are randomly selected" (p. 235). The researcher randomly selected eight different departments of the UoB in order to generalize the results of the study to whole population of university. The students present in the class were asked to fill the questionnaires.

Table 1. Departments and the number of participants

\begin{tabular}{ll}
\hline Department & Number of Participants \\
\hline Journalism and Mass communication & 29 \\
Urdu & 14 \\
English & 28 \\
Islamic Studies & 16 \\
Mathematics & 19 \\
Chemistry & 44 \\
\hline
\end{tabular}




\begin{tabular}{ll}
\hline Biochemistry & 26 \\
Education & 24 \\
Total participants & 200 \\
\hline
\end{tabular}

Total participants of this study were 200 students who completed the given questionnaires: out of which 78 were female students and 128 were male students. All the students were enrolled in second semester of M.Sc., M.A. and M.Ed. programs and in terms of age they were in their early twenties. Reason behind choosing students of second semester was that they were familiar with the university environment and they had studied English courses in first semester. All students belonged to multilingual backgrounds. They were learning English in EFL context. The above-mentioned table reveals the number of students included from each department.

\subsection{Procedure and Instrument}

The researcher presented a questionnaire to each participant. Students were informed in advance that the questionnaires distributed to them were only for the sake of research not for any personal benefit. They were asked to fill the questionnaire anonymously. In participant profile, only the gender was asked in the questionnaire. The data were collected inside the classroom during the class time after taking permission from the teacher of respective class. There were two subsections in the questionnaire of the present study. Those two subsections were social support and FLA.

\subsubsection{Social Support}

The subsection on social support was adapted from a study of immersion students by MacIntyre, Baker, Clément and Conrod (2001). MacIntyre et al. (2001) designed this questionnaire for French students living in Canada. They presented it in English to them because the native language of the participants was English. The reason to include social support in the current study was to determine whether parents, teachers, siblings, and friends had an impact on a learner's WTC in English inside the classroom. In order to adapt the questionnaire for the present study, the researcher made certain modifications according to the Pakistani EFL context. It consisted of total six items to test subjective norms (Ajzen, 1991). Students were asked to respond "yes" or "no" to questions about support, they received from mother, father, teacher, favourite sibling, best friend, and other friend for L2 learning. These items were not used as a scale, rather they were used individually.

\subsubsection{Foreign Language Classroom Anxiety Scale (FLCAS)}

The present study focused on WTC in all four skills of English language; therefore, FLCAS was adapted to measure students' anxiety in EFL classroom. This scale was originally developed by Horwitz and his associates and was used all over the world to determine emotional attitudes among foreign language learners (Horwitz, Horwitz, \& Cope, 1986). The modified version of FLCAS by Yim and Yu (2011) was used for the current study. The FLCAS was based on 16 items. Items from one to 10 were based on oral classroom anxiety, whereas items from 11 to 16 were based on low self-confidence. These overall items formulated the overall foreign language anxiety in an EFL classroom. Five options for each item were given which ranged from strongly agree to strongly disagree.

\section{Results}

This study addressed the following research objectives:

- If there is any impact of social support on students' willingness to communicate in English inside the classroom

- If there is any impact of anxiety on students' willingness to communicate in English inside the classroom

For the data analysis of first research objective, the descriptive statistics of available support were measured. Descriptive statistics is the numerical representation of performance of participants in the questionnaires presented to them. The possible impact of social support on learners' WTC was calculated through t-tests. Statistical Package for Social Sciences (SPSS) version 24 for Windows was used as a fundamental statistical analysis tool to make data analysis easy.

For the data analysis of second research objective, regression analysis was used. FLCAS was used to measure the anxiety. Data was analysed by using simple linear regression method. For this research question as well, SPSS 24 for Windows was used as a statistical analysis tool. 


\subsection{Results of First Research Objective}

To investigate the first research objective of the study, "If there is any impact of social support on students' willingness to communicate in English inside the classroom", independent-samples t-test was performed in the SPSS. The support of teachers, friends, siblings and parents was examined for this purpose. Social support was simply defined as, "Person X (e.g., my teachers) want me to speak English". In Table 2, descriptive statistics of available social support for English language learners are given. As shown in the table given below, number of students for each response (yes or no) is given along with the mean and standard deviation for each item.

Table 2. Descriptive statistics of available social support for English language learners

\begin{tabular}{lllllll}
\hline Social Support & \multicolumn{3}{c}{ Yes } & & & No \\
\cline { 2 - 7 } & $\mathrm{N}$ & $\mathrm{M}$ & $\mathrm{SD}$ & $\mathrm{N}$ & $\mathrm{M}$ & $\mathrm{SD}$ \\
\cline { 2 - 7 } Father's Support & 99 & 3.15 & .74 & 101 & 2.92 & .76 \\
Mother's Support & 95 & 3.08 & .73 & 105 & 3.71 & .87 \\
Siblings' support & 134 & 3.01 & .76 & 66 & 3.09 & .75 \\
Teachers' Support & 101 & 3.21 & .71 & 99 & 2.86 & .76 \\
Best friend's support & 129 & 3.23 & .69 & 71 & 2.69 & .74 \\
Other friends' support & 123 & 3.19 & .73 & 77 & 2.79 & .73 \\
\hline
\end{tabular}

Table 3. Results of t-tests

\begin{tabular}{llll}
\cline { 2 - 4 } Social Support & T & Df & Sig. \\
\cline { 2 - 2 } & 2.073 & 198 & $.039^{*}$ \\
Mother's Support & 1.271 & 198 & .051 \\
Siblings' Support & -.752 & 198 & .453 \\
Teachers' Support & 3.437 & 198 & $.000^{* *}$ \\
Best friend's Support & 5.250 & 198 & $.000^{* *}$ \\
Other friends' Support & 3.696 & 198 & $.000^{* *}$ \\
\hline
\end{tabular}

Note. ${ }^{*} \mathrm{P}<0.05,{ }^{* *} \mathrm{P}<0.001$.

Table 3 above examined the possible effect of available social support on English language learners' WTC. The magnitude of effect of independent variable (social support) on the dependent variable (WTC) was calculated using Cohen's D formula: Eta squared $=\mathfrak{t}^{2} / \mathrm{t}^{2}+(\mathrm{N} 1+\mathrm{N} 2-2)$ and it is interpreted as ".01 = small effect, $.06=$ moderate effect, .14 = large effect" (Cohen, 1988).

The findings of independent-samples t-tests revealed that father support had an impact on learners' WTC, $\mathrm{t}(198)$ $=2.073, \mathrm{p}<0.05$. The magnitude of impact was small (et squared $=0.02$ ). Teacher support also exerted an impact on learners' WTC, $\mathrm{t}(198)=3.437, \mathrm{p}<0.001$. The magnitude of impact was a bit below moderate (et squared $=0.05$ ). Moreover, best friend support had an impact on learners' WTC significantly and positively, $\mathrm{t}$ $(198)=5.250, \mathrm{p}<0.001$. The magnitude of impact was large (et squared $=0.122$ ). On the other hand, other friends support also exerted an impact on learners' WTC, t $(198)=3.696, \mathrm{p}<.001$. The magnitude of other friends' support impact was moderate (et squared $=0.06$ ). Lastly, mother support (et squared $=0.008$ ) and siblings support (et squared $=0.002$ ) did not have any significant impact on WTC of learners. These results suggest that increase in the father support, teachers support, best friends support, and other friends support enhanced learners' WTC in English language. Contrarily, mother support and siblings support did not affect learners' WTC $(\mathrm{P}>0.05)$.

\subsection{Results of Second Research Objective}

To investigate the second research objective of the study, "If there is any impact of anxiety on students' willingness to communicate in English inside the classroom", simple linear regression was run in the SPSS. Since regression analysis emanates a number of assumptions. Therefore, prior to performing simple linear regression, the data were assessed in terms of normality, multicollinearity, and homoscedasticity. The assumption of normality was evaluated by assessing a normal P-P plot. In the Figure 1 below, it can be observed that the data were normally distributed and did not deviate from the normal line. Given the multicollinearity assumption, a variance inflation factor (VIF) was examined. Data show multicollinearity when the VIF value exceeds 10. This assumption was met as the VIF value in the current data was well below the cut-off point as highlighted in the Table 6 below. Lastly, the assumption of homoscedasticity was examined by assessing the scatter plot in which the data were equally scattered around zero. 
Data Analysis for the research objective "if there is any impact of anxiety on students" willingness to communicate in English inside the classroom" is as follows.

Table 4. Model summary

\begin{tabular}{lllll}
\hline Model & RR & R Square & Adjusted R Square & Std. Error of the Estimate \\
\hline 1 & $.452^{\mathrm{a}}$ & .204 & .200 & .67203 \\
\hline
\end{tabular}

Note. a. Predictors: (Constant), Anxiety; b. Dependent Variable: Willingness to Communicate.

Table 5. Significance of the model

\begin{tabular}{llllll}
\hline Model & Sum of Squares & df & Mean Square & F & Sig. \\
\hline Regression & 22.898 & 1 & 22.898 & 50.701 & .000 \\
Residual & 89.423 & 198 & .452 & & \\
Total & 112.321 & 199 & & & \\
\hline
\end{tabular}

Note. a. Dependent Variable: Willingness to Communicate; b. Predictors: (Constant), Anxiety.

Table 6. Simple linear regression predicting WTC

\begin{tabular}{llllll}
\hline Model & B & T & Sig. & VIF \\
\hline Anxiety & -.53 & -7.12 & .000 & 1.00 \\
\hline
\end{tabular}

Note. $\mathrm{F}(1,98)=50.70, \mathrm{p}<.001$.

The model outlined in Tables 4 and 5 above was significant to predict learners' WTC in classroom context, $\mathrm{R}^{2}$ $=.204, \mathrm{R}^{2}$ adj $=.200, \mathrm{~F}(1.98)=50.70, \mathrm{p}<.001$. The overall model accounted for $20 \%$ of the variance in learners' WTC. To calculate the effect size of anxiety on learners' WTC, Cohen's $f^{2}$ was used (e.g., $f 2=R 2 / 1-R^{2}$ ). The outcome is interpreted as, "small effect $\left(f^{2}=0.02\right)$, medium effect $\left(f^{2}=0.1\right)$, and large effect $\left(f^{2}=0.35\right)$ " (Cohen, 1992 , p. 157). The calculated $f 2=.26$ showed the medium effect of anxiety on learners' WTC.Additionally, as illustrated in Table 6 , anxiety $(\beta=-.53, t=-7.12, p<.001)$ predicted learners' WTC negatively. These overall findings suggest that the decrease in the score of anxiety enhances English language learners' WTC and vice versa.

\section{Discussion}

First research objective investigated the impact of social support on students' willingness to communicate in English inside the classroom. The descriptive statistical analysis of available social support for English language learning indicated that learners received highest level of support from their best friend and teachers. Their responses indicated that they received lowest support from their mothers and siblings. After finding out the level of available social support, the magnitude of impact of social support (independent variable) on WTC (dependent variable) was checked by using Cohen's D formula. The results revealed that the magnitude of impact of support from best friend was the largest amongst all and the level of support from mother and siblings was negligible. The data analysis suggests that the postgraduate students of UoB do not receive much appreciation from their mothers to go and communicate in English inside the classrooms or in real world situations. This finding may be explained in relation to cultural values of family system in Balochistan where people are appreciated to only talk in their mother tongue in real life situations since childhood. The cultural values related to owning their regional languages are deeply rooted in the society of Balochistan, which in terms of keeping the local languages alive is immensely a great effort. In the current study the selected participants of research belonged to different family backgrounds with different native languages. By the time they entered university life, they were proficient and fluent speakers of their own languages. The researcher generated a hypothesis prior to data collection, while residing in Quetta and keenly observing the university mates, learners generally do not receive much support from their family. The results strengthened the assumption of the researcher.

The findings of past research studies in EFL contexts are similar to the findings of this research study.A study on French immersion students, 79 selected participants revealed similar findings (MacIntyre et al., 2001). The magnitude of impact of best friend support on their L2 WTC inside the classroom was highest and the magnitude of teachers' support was also considerably high. A study in Korean EFL context investigated L2 WTC of Korean university students inside the classroom (Jung, 2011). Korean students showed more willingness to talk in English with their close friends than with strangers and in small groups than large groups. Another study was 
conducted in EFL context of Iran (Khajavy, Ghonsooly, HosseiniFatemi, \& Choi, 2016). According to the study, support of teacher in Iranian learners' WTC had highest loadings. This study collected data from 243 undergraduate university students. These students were from two different universities of a city in Iran. Data analysis revealed that teachers' support in the classroom exerted a major effect on communicative competence and L2 WTC in the classrooms. Mari, Pathan and Shahriar (2011) conducted a study in Pakistani EFL context at Shah Abdul Latif University, Khairpur. This study collected data from 100 university students and demonstrated similar results. According to the results of this study, participants were more willing to communicate with friends than with strangers. Competence level of those students was high while communicating with their friends.

All these studies used different instruments but the results achieved were generally similar. Learners exhibited high levels of WTC with their close friends or in other words, they were more comfortable in talking to peers. Further analysis reveals another similar thing in all these studies and the present study: an Asian EFL context. In one way or the other way, these studies are in relation with the findings of the present study. Analysis shows that there is an impact of social support on learners' WTC in English inside the classrooms. The reason learners get more support from their best friends than siblings is that one spends time with siblings in informal settings whereas, best friends' support matters the most to the learners. According to the results, teachers' support was also found to have a significant impact on learners' WTC in L2 inside the classroom. The reason behind it is that, in Pakistani context, teachers have huge amount of authority in the classrooms and they dominate their students. Secondly, in Pakistani culture students give high respect to their teachers and their advice and support has a huge impact on learners' learning. That is why their support to communicate in English and their motivation also casts an impact on learners' WTC in English inside the classrooms

Second research objective investigated the impact of anxiety on students' willingness to communicate in English inside the classroom. According to the data analysis, decreased anxiety enhances WTC of learners in English inside the classroom and vice versa. These results are also consistent with those of previous research studies in EFL contexts. Khajavy et al. (2016) conducted a research study in an Iranian EFL context. They collected data from 243 undergraduate university students of two different universities in an Iranian city by using questionnaires. The results of the study depicted that hostile and competitive classroom atmosphere exert stress on learners due to which they feel foreign language anxiety in classrooms. It decreases their WTC in L2 in the classroom and acts as a barrier towards their L2 competence and speech proficiency. This Iranian study suggested that positive role of teacher can decrease learners' anxiety by providing them with relaxing and supportive language learning environment. To create such environment, acceptance of errors both at the end of peer learners and teachers is necessary. Another study in Iranian EFL context also demonstrated same results (Ghonsooly et al., 2012). Data were collected from 158 Iranian undergraduate students by using questionnaire.

The findings of the study showed that there was a negative relation between WTC in L2 and anxiety. Major factor behind this anxiety was fear of negative evaluation in this study as well. The results of the present study also demonstrated a negative relation between learners' L2 WTC and anxiety. Major contributing factor behind decreased level of learners' WTC in English was a fear of negative evaluation. Syed (2016) conducted an empirical study of Pakistani EFL learners where data was collected from postgraduate business students of a Pakistani university. After analyzing the data, his study indicated that learners' anxiety was related to contextual factors that also included lack of preparation of students in advance. When students were not prepared in advance, they were surrounded by nervousness. This sense of nervousness declined their L2 WTC. This study demonstrated an inverse relation between motivation and anxiety through data analysis. High motivation level is linked with reduced anxiety among language learners. Xie (2011) conducted a study in EFL context of China. He collected data from secondary school students in Rural China. According to the findings, language anxiety was a key factor affecting L2 WTC of Chinese students. Familiarity with the text decreased students' language anxiety while reading it aloud in the classroom. Manipuspika (2018) conducted a research study in EFL context of Indonesia in which the researcher tried to find out the relationship between anxiety and L2 WTC. She used questionnaires to collect data from Indonesian university students. The findings of the study were similar to those of present study. According to the findings of the study, there was a strong correlation between Indonesian EFL learners' anxiety and their WTC in English.

Although above-mentioned studies used different instruments and different age groups of the participants of these studies, the results were generally similar that anxiety had an influence on students' WTC in English inside the classrooms. The findings of the present study were also same that increased level of language anxiety led to decreased level of WTC in L2. 


\subsection{Pedagogical Implications}

These findings have implications in EFL classrooms of Pakistani multilingual community. These results can be generalised to all other universities of Balochistan while keeping in mind the target population of the present study. Since social support has a significant impact on students' willingness to communicate in English, WTC should not be seen independently. The results of the present study suggest that increase in support from teachers, friends and parents can have a great magnitude of impact on students' L2 WTC. In order to increase UoB students' L2 WTC, teachers as well as learners need to look at the broader picture of the context. The role of the parents' support needs to be considerate in enhancing their children's WTC in classrooms.

Foreign language anxiety (FLA) has a significant impact on students' WTC inside the classrooms. Increase in anxiety leads to decrease in students' WTC and vice versa. Much research has testified adverse impact of anxiety on students' WTC. Teachers need to release students' anxiety and for this purpose, they can ask them to self-rate their language proficiency. Being their own judge will facilitate them to be better learners and will ease their anxiety. It will help them to figure out that which part of language learning caused them the most anxiety. In order to make students' feel at ease, teachers can share their own experiences as well. They can tell their students that they are not alone in this English language-learning journey. Every non-native learner shares the same anxiety during second language learning process. They can share stories from their learning age when they made the same mistakes. It eases students' anxiety and creates a mindset among them that making mistakes in classroom is a natural phenomenon and they will not be criticised by their teachers and peers for these mistakes. In other words, teachers can convince their students to open their mouth in the classrooms because without participating, they will never learn a language. The end goal of a language should not be to write in good grammar and fancy words, rather to be proficient speakers. Since students feel comfortable in small groups in EFL classrooms, teachers should give preference to small group discussions instead of class discussions.

\subsection{Limitations of This Study and Recommendations for Future Studies}

The present study has so many limitations that need to be discussed. One evident limitation of this study was a small sample size, that too of selected departments from UoB. Since the targeted population for this study was postgraduate university students in Balochistan, the findings can be generalised to this group with certainty. This study was conducted while keeping in mind the contextual settings of Balocistan. Therefore, the results can further be generalised to the contextual settings of other universities in Balochistan only. However, any further generalisation to contexts of developed cities of other provinces with larger universities with better facilities may not seem to be possible. The academic background of the students and less provincial budget for education sector could be a strong factor to make further generalization possible.

The present study was not an experimental study. This study only examined the impact of social support and anxiety on students' WTC inside the classroom. Therefore, it does not give any cause and effect relationship. The predictions given in the study are based on analysis of the research data. The questionnaire data, collected from participants, also have limitations as the data provided by the students were totally based on their perceptions. The present study was based on self-report questionnaires and not on observable facts. The issue with self-report data is that there is always a possibility that the participants' self-report was probably not consistent with their actual performance in the classrooms. Future studies in this area should consider classroom observations or interviews of participants to counter check the results of questionnaire data.

\section{Conclusion}

This research presented detailed analysis of the impact of social support and foreign language anxiety on students' L2 WTC. It aimed at finding out the impact of support that students receive from parents, siblings, teachers, and friends with their level of WTC in English inside the classroom in Pakistani EFL context. L2 WTC is a complex and situational phenomenon. It is directly related to the magnitude of social support learners receive from friends, family, and teachers. According to the results, the magnitude of impact of social support from best friend was the largest on learners' WTC. The students of UoB did not receive much appreciation and support from their mothers and siblings to communicate in English inside the classrooms or in real world situations. Cultural settings of the place of present study go in favour of these findings where students come from different cultural and lingual backgrounds.

It also aimed at finding out the impact of anxiety on students' L2 WTC inside the classrooms. The questionnaire used FLCAS to find out the impact of anxiety on participants' WTC in L2 inside the classroom. The data suggested that decreased anxiety enhanced learners' WTC inside the classrooms and vice versa. Hostile and competitive classroom environments lead to high levels of stress among students. Moreover, in EFL contexts, learners are surrounded by the fear of negative judgment, which also contribute to their increased anxiety in the 
classrooms. Preparation in advance for classrooms participation also leads to decrease in anxiety in the classroom. Students' familiarity with the study material in advance reduces learners' language anxiety in the class while reading it out aloud.

\section{References}

Ajzen, I. (1991). The theory of planned behaviour. Organizational Behaviour and Human Decision Processes, 50(2), 179-211. https://doi.org/10.1016/0749-5978(91)90020-T

Ajzen, I., \& Fishbein, M. (1980). Understanding attitudes and predicting social behaviour. Englewood Cliffs, NJ: Prentice Hall.

Andrade, M., \& Williams, K. (2009). Foreign language learning anxiety in Japanese EFL university classes: Physical, emotional, expressive, and verbal reactions. Sophia Junior College Faculty Journal, 29(1), 1-24.

Baker, S. C., \& MacIntyre, P. D. (2000). The role of gender and immersion in communication and second language orientations. Language Learning, 50(2), 311-341. https://doi.org/10.1111/0023-8333.00119

Bernales, C. (2016). Towards a comprehensive concept of willingness to communicate: Learners' predicted and self-reported participation in the foreign language classroom. System, 56, 1-12. https://doi.org/10.1016/j.system.2015.11.002

Boo, Z., Dörnyei, Z., \& Ryan, S. (2015). L2 motivation research 2005-2014: Understanding a publication surge and a changing landscape. System, 55, 145-157. https://doi.org/10.1016/j.system.2015.10.006

Cao, Y., \& Philp, J. (2006). Interactional context and willingness to communicate: A comparison of behaviour in whole class, group and dyadic interaction. System, 34(4), 480-493. https://doi.org/10.1016/j.system.2006.05.002

Cohen, J. (1988). Statistical power analysis for the behavioural sciences (2nd ed.). NJ: Laurence Erlbaum Associates, Publishers, Hillsdale.

de Saint Léger, D., \& Storch, N. (2009). Learners' perceptions and attitudes: Implications for willingness to communicate in an L2 classroom. System, 37(2), 269-285. https://doi.org/10.1016/j.system.2009.01.001

Department of Education, Policy Planning and Implementation Unit. (2014). Balochistan education sector plan 2014-2018. Retrieved https://planipolis.iiep.unesco.org/en/2014/balochistan-education-sector-plan-2014-2018-besp-6243

Dörnyei, Z. (2003). Attitudes, orientations, and motivations in language learning: Advances in theory, research, and applications. Language Learning, 53(S1), 3-32. https://doi.org/10.1111/1467-9922.53222

Dörnyei, Z., \& Ushioda, E. (Eds.) (2009). Motivation, language identity and the L2self. Bristol: Multilingual Matters. https://doi.org/10.21832/9781847691293

Effiong, M. (2013). Factors influencing foreign language classroom anxiety: an investigation of English learners in four Japanese universities. Doctoral thesis, University of Southampton, England. Retrieved from https://eprints.soton.ac.uk/367372/1/Okon\%2520Effiong\%2520PhD\%2520Thesis.pdf

Fallah, N. (2014). Willingness to communicate in English, communication self-confidence, motivation, shyness and teacher immediacy among Iranian English-major undergraduates: A structural equation modelling approach. Learning and Individual Differences, 30, 140-147.https://doi.org/10.1016/j.lindif.2013.12.006

Ghonsooly, B., Khajavy, G. H., \& Asadpour, S. F. (2012). Willingness to communicate in English among Iranian non-English major university students. Journal of Language and Social Psychology, 31(2), 197211. https://doi.org/10.1177/0261927X12438538

Horwitz, E. K., Horwitz, M. B., \& Cope, J. (1986). Foreign language classroom anxiety. The Modern Language Journal, 70(2), 125-132. https://doi.org/10.1111/j.1540-4781.1986.tb05256.x

Joe, H. K., Hiver, P., \& Al-Hoorie, A. H. (2017). Classroom social climate, self-determined motivation, willingness to communicate, and achievement: A study of structural relationships in instructed second language settings. Learning and Individual Differences, 53, 133-144. https://doi.org/10.1016/j.lindif.2016.11.005

Johnson, B., \& Christensen, L. (2008). Educational research: Quantitative, qualitative, and mixed approaches (4th ed.). California, CA: SAGE Publications.

Jung, M. A. (2011). Korean EFL university students' willingness to communicate in English. Doctoral dissertation, Indiana University, Bloomington.

Retrieved from 
https://search.proquest.com/openview/6bec18eb9dfafd4d0a8ae0faa678262f/1?pq-origsite=gscholar\&cbl=18 $750 \&$ diss $=\mathrm{y}$

Khajavy, G. H., Ghonsooly, B., Hosseini, F. A., \& Choi, C. W. (2016). Willingness to communicate in English: A microsystem model in the Iranian EFL classroom context. TESOL Quarterly, 50(1), 154-180. https://doi.org/10.1002/tesq.204

Khan, H. I. (2013). An investigation of two universities' postgraduate students and their teachers' perceptions of policy and practice of English medium of instruction (EMI) in Pakistani universities. Doctoral dissertation, University of Glasgow, Scotland, United Kingdom. Retrieved from http://theses.gla.ac.uk/4451/1/2013Khanphd2.pdf

Kim, S. J. (2004). Exploring willingness to communicate (WTC) in English among Korean EFL (English as a foreign language) students in Korea: WTC as a predictor of success in second language acquisition. Doctoral thesis, The Ohio State University, Columbus, Ohio. Retrieved from https://etd.ohiolink.edu/!etd.send_file?accession=osu1101267838\&disposition=inline

Lantolf, J. P., \& Thorne, S. L. (2006). Sociocultural theory and the genesis of second language development. Oxford: Oxford University Press.

Lin, Y. T. (2019). Taiwanese EFL learners' willingness to communicate in English in the classroom: Impacts of personality, affect, motivation, and communication confidence. The Asia-Pacific Education Researcher, 28(2), 101-113. https://doi.org/10.1007/s40299-018-0417-y

Liu, M. (2005). Reticence, anxiety and performance of Chinese university students in oral English lessons and tests. Doctoral thesis, Chinese University of Hong Kong, Hong Kong. Retrieved from https://search.proquest.com/openview/362156111752d9cf8a412311 f98321bf/1?pq-origsite=gscholar\&cbl= $18750 \&$ diss $=\mathrm{y}$

Liu, M., \& Jackson, J. (2009). Reticence in Chinese EFL students at varied proficiency levels. TESL Canada Journal, 26(2), 65-81. https://doi.org/10.18806/tesl.v26i2.415

MacIntyre, P. D., Baker, S. C., Clément, R., \& Conrod, S. (2001). Willingness to communicate, social support, and language-learning orientations of immersion students. Studies in Second Language Acquisition, 23(3), 369-388. https://doi.org/10.1017/S0272263101003035

MacIntyre, P. D., Baker, S. C., Clément, R., \& Donovan, L. A. (2002). Sex and age effects on willingness to communicate, anxiety, perceived competence, and L2 motivation among junior high school French immersion students. Language Learning Journal, 52(3), 537-564. https://doi.org/10.1111/1467-9922.00194

MacIntyre, P. D., Burns, C., \& Jessome, A. (2011). Ambivalence about communicating in a second language: A qualitative study of French immersion students' willingness to communicate. The Modern Language Journal, 95(1), 81-96. https://doi.org/10.1111/j.1540-4781.2010.01141.x

MacIntyre, P. D., Dörnyei, Z., Clément, R., \& Noels, K. A. (1998). Conceptualizing willingness to communicate in a L2: A situational model of L2 confidence and affiliation. The Modern Language Journal, 82(4), 545562. https://doi.org/10.1111/j.1540-4781.1998.tb05543.x

MacIntyre, P. D., \& Doucette, J. (2010). Willingness to communicate and action control. System, 38(2), 161-171. https://doi.org/10.1016/j.system.2009.12.013

Manipuspika, Y. S. (2018). Correlation between anxiety and willingness to communicate in the Indonesian EFL context. Arab World English Journal, 9(2), 200-217. https://doi.org/10.24093/awej/vol9no2.14

Mari, M., Pathan, H., \& Shahriar, A. (2011). Willingness to communicate in L2: A perception of Pakistani university students. ELF Annual Research Journal, 13, 65-82.

Matsuda, A. (2012). Principles and practices of teaching English as an international language (vol. 25). Bristol: Multilingual Matters. https://doi.org/10.21832/9781847697042

Peng, J. E. (2012). Towards an ecological understanding of willingness to communicate in EFL classrooms in China. System, 40(2), 203-213. https://doi.org/10.1016/j.system.2012.02.002

Riasati, M. J. (2012). EFL learners' perception of factors influencing willingness to speak English in language classrooms: A qualitative study. World Applied Sciences Journal, 17(10), 1287-1297.

Shamim, F. (1996). In or out of the action zone: Location as a feature of interaction in large ESL classes in Pakistan. In K. M. Bailey, D. Nunan \& M. Swan (Eds.), Voices from the language classroom: Qualitative 
research in second language education (pp. 123-144). Cambridge: Cambridge University Press.

Shamim, F. (2008). Trends, issues and challenges in English language education in Pakistan. Asia Pacific Journal of Education, 28(3), 235-249. https://doi.org/10.1080/02188790802267324

Shao, Q., \& Gao, X. A. (2016). Reticence and willingness to communicate (WTC) of East Asian language learners. System, 63, 115-120. https://doi.org/10.1016/j.system.2016.10.001

Syed, H. A. S. (2016). Dynamics of variables underlying willingness to communicate (WTC) in English (L2): A case study of postgraduate business students at a university classroom in Sukkur, Pakistan. Doctoral dissertation, University of York, England. Retrieved from http://etheses.whiterose.ac.uk/15743/1/Complete\%20draft\%20of\%20thesis\%20PDF\%20\%281\%29.pdf

Watanabe, M. (2013). Willingness to communicate and Japanese high school English learners. JALT Journal, 35(2), 153-172.

Wen, W. P., \& Clément, R. (2003). A Chinese conceptualisation of willingness to communicate in ESL. Language Culture and Curriculum, 16(1), 18-38. https://doi.org/10.1080/07908310308666654

Xie, Q. M. (2011). Willingness to communicate in English among secondary school students in the rural Chinese English as a foreign language (EFL) classroom. Doctoral dissertation, Auckland University of Technology, New Zealand. Retrieved from https://openrepository.aut.ac.nz/bitstream/handle/10292/2548/xieq.pdf?sequence=3

Yashima, T. (2002). Willingness to communicate in a second language: The Japanese EFL context. The Modern Language Journal, 86(1), 54-66. https://doi.org/10.1111/1540-4781.00136

Yim, S. Y., \& Yu, Y. L. (2011). Validating the English learning anxiety scale for primary school students in Korea. English Teaching, 66(2), 101-121.https://doi.org/10.15858/engtea.66.2.201106.101

Zarrinabadi, N. (2014). Communicating in a second language: Investigating the effect of teachers on learners' willingness to communicate. System, 42, 288-295.https://doi.org/10.1016/j.system.2013.12.014

\section{Copyrights}

Copyright for this article is retained by the author, with first publication rights granted to the journal.

This is an open-access article distributed under the terms and conditions of the Creative Commons Attribution license (http://creativecommons.org/licenses/by/4.0/). 